\title{
CARE OF THE INSANE
}

\section{ASYLUM NURSING*}

BY MRS. CHAPMAN

Formerly Matron of Whittingham, Leavesden, and Claybury Asylums, Honorary Treasurer of Association of Asylum Workers, England

THE increase of insanity in the United Kingdom of Great Britain during the last decades of the nineteenth century is an ominous fact, and one to be seriously considered by all those interested in the progress of the nation.

On the authority of the Lunacy Commissioners, as expressed in their report for 1900 , it is stated there existed as a registered lunatic one in three hundred of the total population. This fact ought to be sufficient to enable anyone to realize the gravity of the situation. Notwithstanding, there is a great deal of apathy nong the general public as regards this development of the various forins if mental disease. It is not as yet recognized widely that cases of mental break-down require equal care and skill in their treatment at the hands of the mental nurse as those which are treated in the ordinary hospital. The efficiency and ability which have slowly come to be regarded as the necessary qualifications of the hospital nurse are not as yet expected to the same degree in the asylum nurse by the public. Much has been done by coopperation and methodical instruction to raise the general standard of hospital nursing and attain the highest efficiency, but with the exception of the efforts made by the Medico-Psychological Association of Great Britain and Ireland and some isolated schemes at two or three asylums very little has been inaugurated by the authorities responsible for the maintenance and for the efficient working of the asylums under their control. Here for years has been a policy of "laissez nous faire."

The stimulus which the educational movement in England has experienced the last few years is beginning to arouse interest in circles outside that which is actually engaged in asylum work. The value of systematic training in any profession is now recognized, and the great body of ratepayers, who support these institutions for the care of the insane, are slowly awakening to the fact that the highest economic efficiency is to be obtained by the promotion of the intellectual efficiency of all those engaged in the work of asylums. There is forming a consensus of opinion that to deal adequately with the problems of mental disease and of its alarming increase intelligence must be allied with experience, and that

* Read by title at the Congress of Nurses in Buffalo. 
the perceptive powers of the nurse, in order to meet the varying psychological manifestations of mental disease readily and resourcefully, must be trained to a high degree. Asylums should not be regarded as places where unskilled labor may find a congenial outlet for its energies. The indifference of the past has been great, but the rising interest in the question of efficient mental nursing in our asylums now being manifested is a source of encouragement and hope to the advocates of a better order of things.

There is need to refute the opinion that a nurse may consider herself adequately equipped for her profession without any knowledge of mental disease. If nursing is to be viewed comprehensively, surely all phases of disease should be included in the curriculum of studies laid down for training the intelligence of the nurse. Any system which devotes its attention to only one side of the phases of human disease lacks comprehension. Attention solely directed to the care and treatment of disease as manifested in an ordinary hospital cannot give a complete view of the maladies $t$.. wich the human organism is subject; rather what is attained is a specialized form of knowledge. It would be interesting to have the opinions of those who have passed through the normal period of training in a hospital as to the completeness of their qualifications. Can they regard themselves as fully trained nurses? Many probably have not viewed the subject in this light, yet if the term "trained nurse" is to have a comprehensive connotation, some doubts must arise in their minds. The hospital-trained nurse cannot regard herself as having had a complete training for her profession as a general nurse unless she has had some experience in mental nursing. The medical superintendent of a large asylum writes on this subject to this effect:

"Looking back on my hospital experience, I cannot help recollecting what a number of 'naughty' patients the nurses in the hospitals insisted on my discharging. Of course, I know now that nearly all these 'naughty' persons were patients with mental symptoms, whom the trained hospital nurse did not know how to manage. They mistook ' madness' for 'badness.' Medical men now are obliged to take a course of lectures on mental disease before they can be qualified for practice. Why should hospital nurses be exempt?"

The experience here stated, probably, is not unique. It points to the fact that there are diseases whose symptoms are not recognized by those whose training is restricted to the hospital sphere alone. The term "trained nurse" has been too long exclusively appropriated by one section of the community of the nursing world. The limitations in the experience gained in the hospital wards should be recognized. 
That gained by another section in the sphere of mental nursing equally justifies the appellation "trained." On this ground the status of the asylum nurse should receive adequate recognition. Her duties are exacting and onerous in the extreme, calling forth all her powers of sympathy, tact, resourcefulness, with the power of infusing hope,-qualifications different in kind to some extent from those demanded in the hospital nurse, yet necessarily essential for obtaining successful results.

The principle of subdivision of labor lies at the base of all attainment of high efficiency, and the concentration of effort upon a certain field of manifestation of human disease is necessary for attaining that skill which is so essential for success in medical nursing. Hospital and asylum nurses are coöperators in the work of alleviating that pain and misery which exist so largely in the world. The work of each is correlated with the other. The mental is intimately conjoined to the physical in the human organism, and efficiency in nursing can only be fully attained by the recognition of this relation between the physical and mental.

As it has been laid down that knowledge of mental disease should be regarded a necessary qualification in the trained nurse, so equally must it be insisted that the mental nurse should go through a course of training on the general lines of the hospital nurse. In the infirmary wards of our large asylums there are always a number of cases requiring medical nursing, which can only be given with efficiency by the asylum nurse after a period of training on the lines laid down for hospital nurses. This has been almost universally recognized in the asylums of the United Kingdom. The medical staff in every important asylum deliver lectures and give demonstrations on the subject of the nursing of the sick. The syllabus of the Medico-Psychological Association is comprehensive, and if thoroughly worked will give a good elementary knowledge of the requirements for efficient nursing in the infirmary wards of an asylum.

It is indispensable for efficiency in an asylum nurse placed in charge of an infirmary ward that she should have this general insight into the requirements for successful medical and surgical nursing. This information should be gained in the early stages of her experience before the study of the psychological phases of insanity as a disease be entered upon. It will enable her to get a better grasp of the relation between the psychical and physical and of the interaction which takes place between them.

In most asylums of the Kingdom there has been made during the last few years by the medical staffs of these institutions a sustained effort to impart a general knowledge of the nursing of the sick. It is now 
regarded as essential in the nurses of the infirmary wards that they should know something of elementary anatomy and physiology, of the care of the sick and the management of helpless and bedridden patients; the making, moving, and changing of beds and body-linen; the prevention and treatment of bedsores; application of fomentations, poultices, counter-irritants, etc.; the giving of baths; administering enemas; using the catheter; preparing food and feeding helpless patients, with the observation of the effects of diet, stimulants, medicine, etc.; the laws of cleanliness and ventilation; the disinfection of utensils, and modes of disinfection in cases of phthisis and fevers; bandaging; first aid in cases of accident; the observation of mental symptoms, such as hallucinations, delusions, stupor, etc., with the special treatment of epileptic, excited, violent, and suicidal patients, and the care of those requiring diversion and companionship; also management of the convalescent.

The following quotations from a speech by Dr. Clouston, of Morningside Asylum, Edinburgh, on the occasion of a presentation to the head nurse of the infirmary wards of that institution after twenty-six years' service, may be interesting as showing the strides made not only in Scotland, but throughout the Kingdom:

"We have met together to show our respect and regard for Mrs. Findlay, head nurse in the female hospital, and to show our appreciation of twenty-six years of faithful service to the institution and to its sick. At the beginning of that time the sick were not as well treated, not as carefully nursed, as they are now. At that time all institutions had no doubt what was called a sick ward, or a sick dormitory, but not a fully equipped and staffed 'hospital.' Shortly after Mrs. Findlay came here we were making great changes in this institution, and we had under a separate roof a building that used to be called 'The Separates.' This building was intended for the very worst class of the female patients, as it was thought that they were not fit to mix with the others at all, and whether curable or incurable, a troublesome patient was sent down to the 'Separates.' Now, the actual effect of gathering together such an explosive element as this was that each patient made the other worse. It was a veritable pandemonium. Following the general ideas of the time, it occurred to me that this building by a thorough alteration could be made into a small hospital, just like a pavilion of the Edinburgh Infirmary, which could be utilized for the nursing of the newly admitted and weak patients, the keynote of its management being nursing and cure, and not detention. This was carried out, and for the first time really in the history of asylums a building fully equipped was used with open doors, with ordinary arrangements, with a full staff of trained 
nurses for the treatment of the mentally afflicted who needed nursing, the hospital being also used for the training of the new nurses. And here comes in Mrs. Findlay's work. She was already in charge of our little ' sick-room,' and I was firmly convinced by the way she discharged her duties there that she would enter fully into the general idea of the new hospital. This she at once realized very fully, and carried out the medical intention that each woman there was a patient laboring under a disease to be nursed and treated. This idea, I assure you, was not then universally prevalent. Mrs. Findlay's success in her work, the way in which she both nursed and superintended the nursing of poor sick women and trained our new nurses, has made this idea take possession of the treatment of the whole of the insane in the country. I am quite sure if my friends, Sir Arthur Mitchell and Sir John Sibbald, were here they would back me up in this very strong statement that Mrs. Findlay's success in an ordinary hospital building, her demonstration that this was a possible thing, and not only possible, but an advance on the whole treatment of the mentally afflicted, was one of the reasons why the Commissioners in Lunacy took up the 'hospital' idea, so that now there is not an institution without such a means of treatment. . . . Now the thorough success of Morningside Hospital Section and its adoption elsewhere, and the general amelioration that one feels has thereby talsen place in the treatment of the mentally afflicted, is a thing to be proud of and grateful for."

The conditions of the service in asylums in Great Britain give cause for some reflection. The continual changing of the staff which arises from dissatisfaction with the secluded character of the life in institutions, combined with the abnormally long hours of duty, together with an inadequate scale of remuneration, is a feature in asylum nursing which needs careful study. The restrictions enforced ten years ago are now felt to be out of place. There has arisen a demand for greater freedom on the part of the staff, and the expression of a desire for wider opportunities for recrcation, a need which can only be met by an extension of holidays and a lessening of the hours of duty. If a high state of cfficiency is ever to be gained in the nursing of the mentally afflicted, it can only be by maintaining a state of permanency among the staff able to supply the result of years of expericncc to meet the exigencies which so often arise in the wards in a manifold variety.

This perpetual ebb and flow among the personnel of the staffs of our asylums has been noted by the Commissioners in Lunacy, and the attention of the ruling authorities of our asylums has been drawn to the fact, and it has been suggested that some determined effort should be made to render the service in our asylums more attractive, both finan- 
cially and socially. At present there is no guaranteed pension for service in the county asylums * of England and Wales, but there is being made a representative effort to promote legislation to attain this end, and so place the asylum nurse upon the same basis as other branches of the civil service of the Kingdom.

In this respect there is a difference between hospital and asylum nursing. There exists a greater need for recreation in the latter. Companionship with dements has a most depressing effect and requires vigorous counteraction to ward off injurious results, while the nervous strain entailed in the care of acute cases of insanity ultimately in a few years reacts upon the nurse and causes a general breakdown unless the motto of "mens sana in corpore sano" is carefully regarded. A true appreciation of this statement can only be gained by those who have had actual experience of the inner life of our asylums and the excessively trying conditions which often exist therein. The effort to maintain a healthy physical tone among the staff of our asylums should meet with every encouragement from the managers of these institutions. A low state of health diminishes the efficiency of the nurse, and the work consequently suffers. However we may regard it, due consideration of the needs of the staff promotes both the medical and economic interests of our asylums. There is expressed a general desire to raise the status and qualifications of the asylum nurse, and some progress in this respect has been made. This can be further advanced by careful selection of candidates. On the whole, it is probable there is better material from which to select female nurses than male. Wider spheres of work for men have a great deal to do with this condition of things, but for those who elect to remain in the service the same course of instruction and training is open as is available to the female nurse, and a man of good character holding the medico-psychological certificate will readily find employment either in an asylum or with a private case. A good moral character is the foundation upon which the successful training of the nurse rests. Asylum nursing makes severe demands on moral qualities of character. Tact, power of self-control, sympathy, and quick perceptive powers are all needcd.

On the authority of Dr. Spence, writing in the Journal of Mental Science in 1899, it may be stated that there is no wide difference existing between the conditions of asylum nursing in England and in America. The development in recent years in America has acted as a stimulus upon the asylums of England, and the facilities for the interchange of ideas which now exist will promote progress in every direction.

* Asylums under the management of the various County Councils. 